\title{
Oral Health Knowledge, Attitude, and Behavior of Nursing and Technical Students in Croatia
}

\author{
Zoran Kovac ${ }^{4}$ Zrinka Puharic ${ }^{2}$ Irena Glazar ${ }^{3}$ Mirna Zulec ${ }^{2}$ \\ ${ }^{1}$ Department of Oral Surgery, Faculty of Dental Medicine, University \\ of Rijeka, Rijeka, Croatia \\ ${ }^{2}$ Professional Study Nursing, Bjelovar University of Applied Sciences, \\ Bjelovar, Croatia \\ ${ }^{3}$ Department of Oral Medicine and Periodontology, Faculty of \\ Dental Medicine, University of Rijeka, Rijeka, Croatia \\ ${ }^{4}$ Department of Prosthodontics, Faculty of Dental Medicine, \\ University of Rijeka, Rijeka, Croatia
}

Tomislav Cabov ${ }^{1}$ Ksenija Eljuga ${ }^{2}$ Petra Nola Fuchs ${ }^{1}$ Maja Kinkela Devcic ${ }^{1}$ Jelena Prpic ${ }^{3}$

\begin{abstract}
Address for correspondence Irena Glazar, PhD, DMD, Department of Oral Medicine and Periodontology, Faculty of Dental Medicine, University of Rijeka, Kresimirova 40/42, 51000 Rijeka, Croatia (e-mail: irena.glazar@fdmri.uniri.hr).
\end{abstract}

Eur J Dent 2022;16:102-108.

\begin{abstract}
Keywords

- attitude

- habits

- knowledge

- oral health

Objective The aim of this study was to test knowledge, attitudes, and behavior of the students from the Bjelovar University of Applied Sciences in relation to oral health, and to determine the respectable differences between students of nursing and technical study programs.

Materials and Methods Students were randomly selected to represent a convenient sample. A total of 140 students from nursing and technical studies were interviewed by using the World health organization Oral Health Questionnaire, adapted to fit the study purposes.

Statistical Analysis Descriptive statistics were used to determine frequency distribution and percentages for all variables. Pearson's Chi-square test was used to compare the proportions. A p-value less than 0.05 was considered to be statistically significant. Results The distribution of participants regarding gender was significantly different between the study programs $(p=0.000)$. Significant difference was also observed in their perceived socioeconomic status $(p=0.001)$. A significant difference was found between the study programs regarding the knowledge whether bad teeth could impair general health $(p=0.001)$, could tooth decay and periodontal disease may be prevented $(p=0.002)$, as well as the importance of regular dental check-ups for prevention of tooth decay $(p=0.028)$. There were significant differences regarding dietary habits and alcohol consumption in the past 30 days between the observed study programs $(p=0.000)$ while no significant differences were found regarding tobacco and tobacco product use $(p=0.170)$.

Conclusion Results obtained and presented in this paper show better knowledge and more favorable habits and behaviors among the students from nursing study program compared with the technical ones. Still all students' habits should be changed to improve oral health. To change attitudes and influence habits, effective oral health promotion programs are needed; not only in colleges, but also in primary and secondary schools.
\end{abstract}

published online

August 24, 2021
DOI https://doi.org/

$10.1055 / \mathrm{s}-0041-1731852$ ISSN 1305-7456 (c) 2021. The Author(s).

This is an open access article published by Thieme under the terms of the Creative Commons Attribution License, permitting unrestricted use, distribution, and reproduction so long as the original work is properly cited. (https://creativecommons. org/licenses/by/4.0/).

Thieme Medical and Scientific Publishers Private Ltd. A-12, Second

Floor, Sector -2, NOIDA -201301, India 


\section{Introduction}

World health organization (WHO) describes oral health as a state of complete well-being and functional ability of the teeth and their supporting tissues required for chewing, talking, and esthetics. ${ }^{1}$ It has been acknowledged that oral health is of great importance for general health. Numerous investigations and a large body of scientific evidence show the relationship between oral health and some systemic diseases such as cardiovascular disease, diabetes, obesity, arthritis, mild cognitive impairment, and even some malignant diseases. ${ }^{2,3}$ Furthermore, oral health is an important indicator of the overall health and well-being, as well as the quality of life. ${ }^{4}$ The most common problems seen in the oral cavity are tooth decay (caries), periodontal diseases, and oral carcinoma. One investigation found that oral diseases were present in 3.9 billion people in the world and were led by tooth decay. ${ }^{5}$ Periodontal diseases were found in approximately $20 \%$ of the world population, while oral carcinoma placed sixth on the list of most common carcinomas in the world. ${ }^{6,7}$ Risk factors associated with oral disease development are related to the lifestyle. All of the above mentioned oral conditions may be related to behavior, attitudes, and knowledge on oral health. Food rich in carbohydrates, tobacco, and alcohol consumption; poor oral hygiene and inadequate dental maintenance contribute to the development of oral diseases. ${ }^{4,6,7}$ Behavior is defined as a constant and usual mode of carrying out something or behaving and is extremely hard to give up, while the attitude is defined as the way in which a person views and evaluates something or someone. Attitude determines our tendencies of behaving in a certain way. ${ }^{8,9}$ Both behavior and attitudes are acquired during one's life and as such may have either positive or negative effect. However, they may be changed and modified by acquisition of knowledge, in this case on the importance of oral health. Many epidemiological investigations demonstrate a connection between environmental and behavioral factors, which may have detrimental effects on health and lead to development of oral diseases. ${ }^{10,11}$ Tooth decay and periodontal diseases are considered as behavioral diseases and may be controlled by altering or modifying certain aspects of lifestyle, in particular adequate maintenance of oral hygiene. Added sugars in food and alcoholic beverages pose the greatest threat related to nutritional habits since they can serve as the energy source for bacteria helping them grow, building plaque deposits, and acids which in turn damage tooth enamel and dentine. ${ }^{12}$ Moreover, numerous investigations confirmed that reduced intake of alcoholic beverages and reduction of tobacco consumption may significantly reduce the risk of oral carcinoma development. ${ }^{13-15}$ Knowledge of the importance of oral health and risk factors for development of oral diseases may have a strong effect on one's behavior and attitudes, with students being the perfect target group since theirs is the very age when most of the behavior and attitudes are defined. ${ }^{14-17}$ It is feasible that students in healthcare sector will have greater scope of knowledge on health issues, since their very choice of future profession means that they are aware of the importance of not only human health, but also the need to participate actively in providing help to others.

The aim of this study was to test knowledge, attitudes, and behavior of the students from the Bjelovar University of Applied Sciences in relation to oral health, and to determine the respectable differences between students of nursing and technical study programs.

\section{Materials and Methods}

This study was conducted at the Bjelovar University of Applied Sciences, Croatia during the academic year 2018/19. Students were randomly selected from the group of freshmen and sophomores of the nursing and technical programs. A total of 140 students were recruited, 70 from each branch. In both study programs, half of the participants were freshmen and half were sophomores. The mean age of all students was $22.79 \pm 6.23$ years.

For the purpose of this investigation, the WHO Oral health survey questionnaire was used, with added questions related to the participants' attitude on oral health. ${ }^{18}$ Before filling out the questionnaire, the participants were informed of the aims and purpose of the investigation and signed the informed consent. The consent form and questionnaire were in no way matched. Therefore, the available data could not be correlated to the participants. The participation was entirely voluntary, and regardless of having been selected randomly, the participants were able to drop out of the investigation at any time. This investigation has been approved by the Ethics Committee of the Bjelovar University of Applied Sciences and the Board for biomedical trials of the Faculty of Health Studies in Rijeka, Croatia.

The questionnaire contained questions referring to general information (age, gender, faculty affiliation, study year, and perceived financial status of the family), oral health information (How many natural teeth, crowns, and implants do you have?/In the past 12 months, did your tooth or mouth problems cause any pain or discomfort?/Do you have any removable dentures?/How would you describe the condition of your teeth and gums? Is it "excellent," "very good," "good," "average," "poor," or "very poor"?), as well as habits and attitudes on oral health (do you believe bad teeth can impair general health?/How often do you clean your teeth?/Do you use any of the following to clean your teeth/Do you use toothpaste to clean your teeth?/Do you use toothpaste that contains fluoride?/How long has it been since you last saw a dentist?/What was the reason of your last visit to the dentist?/Because of the condition of your teeth or mouth, how often have you experienced any of the following problems in the past 12 months? How often do you eat or drink any of the following foods, even in small quantities?/How often do you use any of the following types of tobacco/During the past 30 days, on the days you drank alcohol, how many drinks did you usually drink per day?).

\section{Statistical Analysis}

Statistical analysis was performed by using the Statistical Package for Social Science (SPSS). Descriptive statistics were 
used to determine frequency distribution and percentages for all variables. Pearson's Chi-square test was used to compare the proportions, and Fisher's exact test was adopted if necessary. A $p$-value less than 0.05 was considered to be statistically significant.

\section{Results}

A total of 140 students participated in the study, that is, 35 per each study program and study year. - Table 1 demonstrates the distribution of participants regarding gender with significant difference between the study programs: $84.4 \%$ males in technical programs versus $25.7 \%$ in nursing $(p=0.000$ ). Significant difference was observed in their perceived socioeconomic status, where $17.2 \%$ of students from technical programs viewed their standing as above average versus only $1.4 \%$ of nursing students $(p=0.001)$.

Regarding the questions on the number of teeth in the mouth, crowns, implants, or dentures, no significant differences were observed between the study groups; the same applies for the questions regarding the condition of teeth and gums.

Oral health attitudes are listed in - Table 2. A significant difference has been found between the study programs regarding the question whether bad teeth could impair general health, where $14.1 \%$ of those from technical programs say that they are not sure this is true $(p=0.001)$. Furthermore, the statistically significant differences were observed regarding the statements: "Tooth decay and periodontal disease may be prevented" ( $p=0.002)$ and "Regular dental check-ups are important for the prevention of tooth decay" ( $p=0.028)$. Students from nursing study program agree significantly more often with these statements compared to the technical students.

The answers to the question (how often do you clean your teeth?) are presented in - Table 3 . It is important to note that $46.9 \%$ technical students say that they brush twice a day or more often, compared with $78.6 \%$ of students from nursing program $(p=0.002)$. Dental floss is more frequently used by the nursing students $(p=0.021)$ as it showed at $\boldsymbol{-}$ Table 4 .
As for the dietary habits, there are significant differences regarding consumption of fruit $(p=0.003)$, sweet foods ( $p=$ $0.007)$, carbohydrate-rich foods $(p=0.005)$, and sugar chewing gums $(p=0.010)$.

Finally, there were no significant differences regarding tobacco and tobacco product use $(p=0.170)$, whereas alcohol consumption in the past 30 days ( - Table 5 ) showed significant differences between the observed study programs ( $p=0.000$ ), with $12.5 \%$ of the technical students stating that they consume less than one drink per day, versus $38.6 \%$ of the students from nursing program.

\section{Discussion}

The scope of numerous investigations performed around the globe among people belonging to different age groups has been to gain insight into the knowledge, behavior, and attitudes related to oral health. During the past decades, a significant decrease in prevalence of oral diseases has been observed, especially in developed countries, which has been linked to the awareness of the importance of oral health, implementation of healthy lifestyle, and effective application of prevention programs. ${ }^{19}$ Young people, including students, are an important segment of the society, since their behavior may play a crucial role in the positive change of behavior reflected in the entire community. ${ }^{20,21}$ To increase the effectiveness of the education and prevention programs, one should gain some insight into the knowledge, behavior, and attitudes of this target group. This investigation provided the information on general data, oral health data, attitudes, and behavior regarding oral health in the group of nursing and technical students.

In this study population, there was a statistically significant difference regarding the participants' gender $(p=0.000)$. The questionnaire was distributed to $84.4 \%$ of males attending the technical programs versus $25.7 \%$ in nursing program. Male gender is predominant at the technical programs of the Bjelovar University of Applied Science, whereas the opposite goes for nursing. This result may be explained by the fact that technical study programs are more frequently attended by

Table 1 Sociodemographic data of the participants

\begin{tabular}{|c|c|c|c|c|c|}
\hline & & Technical studies (\%) & Nursing program (\%) & Total (\%) & $p$-Value \\
\hline \multirow[t]{3}{*}{ Gender } & Male & 84.4 & 25.7 & 53.7 & \\
\hline & Female & 15.6 & 74.3 & 46.3 & \\
\hline & Total & 100.0 & 100.0 & 100.0 & \\
\hline \multirow[t]{3}{*}{ Study year } & Freshman & 54.7 & 50.0 & 52.2 & \multirow[t]{3}{*}{0.587} \\
\hline & Sophomore & 45.3 & 50.0 & 47.8 & \\
\hline & Total & 100.0 & 100.0 & 100.0 & \\
\hline \multirow{4}{*}{$\begin{array}{l}\text { How would you rate your } \\
\text { socioeconomic status? }\end{array}$} & Below average & 4.7 & 0.0 & 2.2 & \multirow[t]{4}{*}{0.001} \\
\hline & Average & 78.1 & 98.6 & 88.8 & \\
\hline & Above average & 17.2 & 1.4 & 9.0 & \\
\hline & Total & 100.0 & 100.0 & 100.0 & \\
\hline
\end{tabular}


Table 2 Perceived effect of tooth-related conditions on general health

\begin{tabular}{|c|c|c|c|c|c|}
\hline & & $\begin{array}{l}\text { Technical } \\
\text { studies (\%) }\end{array}$ & Nursing program (\%) & Total (\%) & $p$-Value $(0.001)$ \\
\hline \multirow{4}{*}{$\begin{array}{l}\text { Decayed teeth cannot } \\
\text { affect general health }\end{array}$} & I agree & 82.8 & 100.0 & 91.8 & \\
\hline & I do not agree & 3.1 & 0.0 & 1.5 & \\
\hline & I am not sure & 14.1 & 0.0 & 6.7 & \\
\hline & Total & 100.0 & 100.0 & 100.0 & \\
\hline \multirow{4}{*}{$\begin{array}{l}\text { Tooth decay and per- } \\
\text { iodontal diseases are } \\
\text { preventable }\end{array}$} & I agree & 81.2 & 98.6 & 90.3 & \multirow[t]{4}{*}{0.002} \\
\hline & I do not agree & 3.1 & 1.4 & 2.2 & \\
\hline & I am not sure & 15.6 & 0.0 & 7.5 & \\
\hline & Total & 100.0 & 100.0 & 100.0 & \\
\hline \multirow{4}{*}{$\begin{array}{l}\text { Regular dental check-ups } \\
\text { are important for tooth } \\
\text { decay prevention }\end{array}$} & I agree & 79.7 & 94.3 & 87.3 & \multirow[t]{4}{*}{0.028} \\
\hline & I do not agree & 9.4 & 4.3 & 6.7 & \\
\hline & I am not sure & 10.9 & 1.4 & 6.0 & \\
\hline & Total & 100.0 & 100.0 & 100.0 & \\
\hline \multirow{4}{*}{$\begin{array}{l}\text { I brush teeth regularly to } \\
\text { keep them healthy }\end{array}$} & I agree & 87.5 & 97.1 & 92.5 & \multirow[t]{4}{*}{0.075} \\
\hline & I do not agree & 4.7 & 0.0 & 2.2 & \\
\hline & I am not sure & 7.8 & 2.9 & 5.2 & \\
\hline & Total & 100.0 & 100.0 & 100.0 & \\
\hline \multirow{4}{*}{$\begin{array}{l}\text { Dental esthetics influences } \\
\text { the way others see us }\end{array}$} & I agree & 84.4 & 92.9 & 88.8 & \multirow[t]{4}{*}{0.129} \\
\hline & I do not agree & 1.6 & 2.9 & 2.2 & \\
\hline & I am not sure & 14.1 & 4.3 & 9.0 & \\
\hline & Total & 100.0 & 100.0 & 100.0 & \\
\hline
\end{tabular}

Table 3 Frequency of tooth brushing

\begin{tabular}{|c|c|c|c|c|c|}
\hline & & $\begin{array}{l}\text { Technical } \\
\text { studies (\%) }\end{array}$ & $\begin{array}{l}\text { Nursing } \\
\text { program (\%) }\end{array}$ & Total (\%) & $p$-Value $(0.002)$ \\
\hline \multirow{7}{*}{$\begin{array}{l}\text { How often do } \\
\text { you brush your } \\
\text { teeth? }\end{array}$} & Never & 1.6 & 0.0 & 0.7 & Once a month \\
\hline & 0.0 & 0.0 & 0.0 & 2-3 times a week & 6.2 \\
\hline & 0.0 & 3.0 & Once a week & 0.0 & 0.0 \\
\hline & 0.0 & $\begin{array}{l}\text { 2-6 times a } \\
\text { week }\end{array}$ & 7.8 & 4.3 & 6.0 \\
\hline & Once a day & 37.5 & 17.1 & 26.9 & Twice a day or more \\
\hline & 46.9 & 78.6 & 63.4 & Total & 100.0 \\
\hline & 100.0 & 100.0 & & & \\
\hline
\end{tabular}

men, while females are predominant students at biomedical faculties including nursing programs. This tendency has also been reported by Buccheri ${ }^{22}$ who confirmed that females are more interested in medical study programs than males who prefer technical knowledge. The interest in programs such as computing and electrotechnics is rising due to great technological advances in those fields and possibility of application of the knowledge in almost every line of work. Furthermore, upon completion, students usually face no problems in finding the job while being offered above the average pay levels. It may therefore be expected that more women will apply to those study programs in the future, and not only in Croatia.

Regarding the question on the students socioeconomic status, significant differences were observed between the study programs. Of those interviewed, $17.2 \%$ of the technical students reported their status as above the average compared just $1.4 \%$ of nursing students. These results are not in line with the available investigations demonstrating that technical students are usually more financially vulnerable compared with their biomedical counterparts. Al-Hussaini ${ }^{12}$ analyzed sociodemographic data on medical, pharmacology, and dental students, and $51.5 \%$ of them stated their families had incomes above the average, while $34.9 \%$ stated their family income was average.

- Table 2 showing the students' attitudes regarding the effect dental health on overall health also demonstrates significant differences between study groups. All nursing students were affirmative (100\%) versus $82.8 \%$ of technical 
Table 4 Comparison between the means for oral health maintenance

\begin{tabular}{|c|c|c|c|c|c|}
\hline \multicolumn{2}{|c|}{$\begin{array}{l}\text { Do you use any of the following to } \\
\text { clean your teeth? }\end{array}$} & \multirow{2}{*}{$\begin{array}{l}\begin{array}{l}\text { Technical } \\
\text { studies (\%) }\end{array} \\
100.0\end{array}$} & \multirow{2}{*}{$\begin{array}{l}\text { Nursing } \\
\text { program (\%) } \\
100.0\end{array}$} & \multirow{2}{*}{$\begin{array}{l}\text { Total (\%) } \\
100.0\end{array}$} & \multirow[t]{2}{*}{$p$-Value } \\
\hline Toothbrush & Yes & & & & \\
\hline & No & 0.0 & 0.0 & 0.0 & \\
\hline & Total & 100.0 & 100.0 & 100.0 & \\
\hline \multirow[t]{3}{*}{ Wooden toothpicks } & Yes & 37.5 & 27.1 & 32.1 & \multirow[t]{3}{*}{0.200} \\
\hline & No & 62.5 & 72.9 & 67.9 & \\
\hline & Total & 100.0 & 100.0 & 100.0 & \\
\hline \multirow[t]{3}{*}{ Plastic toothpicks } & Yes & 9.4 & 8.6 & 9.0 & \multirow[t]{3}{*}{0.871} \\
\hline & No & 90.6 & 91.4 & 91.0 & \\
\hline & Total & 100.0 & 100.0 & 100.0 & \\
\hline \multirow[t]{3}{*}{ Dental floss } & Yes & 34.4 & 54.3 & 44.8 & \multirow[t]{3}{*}{0.021} \\
\hline & No & 65.6 & 45.7 & 55.2 & \\
\hline & Total & 100.0 & 100.0 & 100.0 & \\
\hline \multirow[t]{3}{*}{ Chewstick/miswak } & Yes & 3.1 & 1.4 & 2.2 & \multirow[t]{3}{*}{0.507} \\
\hline & No & 96.9 & 98.6 & 97.8 & \\
\hline & Total & 100.0 & 100.0 & 100.0 & \\
\hline \multirow[t]{3}{*}{ Other } & Yes & 10.9 & 8.6 & 9.7 & \multirow[t]{3}{*}{0.644} \\
\hline & No & 89.1 & 91.4 & 90.3 & \\
\hline & Total & 100.0 & 100.0 & 100.0 & \\
\hline
\end{tabular}

Table 5 Alcohol consumption in the past 30 days

\begin{tabular}{|l|l|l|l|}
\hline $\begin{array}{l}\text { During the past } \mathbf{3 0} \text { days, on the days you drank } \\
\text { alcohol, how many drinks did you usually drink } \\
\text { per day? }\end{array}$ & $\begin{array}{l}\text { Technical } \\
\text { studies (\%) }\end{array}$ & $\begin{array}{l}\text { Nursing } \\
\text { program (\%) }\end{array}$ & Total (\%) \\
\hline Less than one & 12.5 & 38.6 & 26.1 \\
\hline 1 drink & 10.9 & 12.9 & 11.9 \\
\hline 2 drinks & 10.9 & 11.4 & 11.2 \\
\hline 3 drinks & 10.9 & 10.0 & 10.4 \\
\hline 4 drinks & 3.1 & 10.0 & 6.7 \\
\hline 5 or more drinks & 45.3 & 17.1 & 30.6 \\
\hline $\begin{array}{l}\text { I have not been drinking any alcohol for the past 30 } \\
\text { days }\end{array}$ & 6.2 & 0.0 & 3.0 \\
\hline Total & 100.0 & 100.0 & 100.0 \\
\hline
\end{tabular}

students. For comparison, Gopikrishn ${ }^{23}$ showed that $73 \%$ of the engineering students and $74.8 \%$ of their nursing counterparts consider dental health as an important factor in general health. As for the question whether tooth decay and periodontal diseases are preventable, $98 \%$ of nursing students said "yes" versus $81.2 \%$ of technical students. Furthermore, $94.3 \%$ of students attending nursing programs think that regular dental check-ups can prevent tooth decay, while $79.7 \%$ of the students from technical programs gave the same answer. Similar data were obtained by Jaramillo ${ }^{24}$ who showed that the nursing students had superior knowledge on oral health compared to the students from technical faculties. Nursing students are the future promoters of the importance of health maintenance and oral health knowledge is implemented in their study programs. Finally, the available results demonstrate that nursing students have more positive attitudes towards the importance of oral health compared to the technical ones.

- Table 3 presents data related to oral habits. Based on the acquired knowledge, one develops habits performed daily usually without thinking. The question ("how often do you brush your teeth?") showed significant differences between the observed study programs, $46.9 \%$ of students from technical programs stated that they brushed twice a day or more, compared to $78 \%$ of those from nursing program who provided the same answer. There are $37.5 \%$ of technical students who brush only once a day versus $17.1 \%$ of the nursing ones, this difference is significant. Kaira et $\mathrm{al}^{25}$ tested 
the knowledge, attitudes, and behavior among the nursing students at the Medical School in India, and they published the results of 111 participants, $48.7 \%$ of students brush their teeth twice a day and $28.9 \%$ of students brush once a day. Results of the investigation presented hereby demonstrate more nursing students brush twice a day compared to the nursing students in India. In another investigation from Lithuania by Pacauskien, ${ }^{26}$ 92\% students from biomedical colleges brush their teeth twice a day, whereas $73.3 \%$ of technical students reported the same habit. If we should compare these results to those hereby presented, students from Croatia demonstrated poorer oral hygiene maintenance habits compared to those from Lithuania.

Dental floss is a valuable addition to oral hygiene maintenance, and it is used by $34.4 \%$ of the students from technical study programs compared with $54.3 \%$ of the students from nursing program. This difference is statistically significant. For comparison, in Lithuania $44.6 \%$ of the biomedical and $17.3 \%$ of the technical final year students use dental floss. ${ }^{26}$ We may conclude that students from the Bjelovar University of Applied Science used dental floss more often.

The question (when did you last visit your dentist?) shows a marking difference between the observed study groups: $32.8 \%$ of the students from technical study programs state less than 6 months compared to $50 \%$ of the students from nursing students. Similarly, very interesting results were obtained by Gopikrishna, ${ }^{23}$ showing that dental check-ups fail to follow the trends. For example, $28.05 \%$ never visit their dentists, while $38.7 \%$ visit the dentist only when they feel the pain. Distribution among the students show that $39.1 \%$ technical students and $34.3 \%$ nursing students visited their dentists only when in pain. As reported in the investigation by Kaira, ${ }^{25}$ $19.8 \%$ of the nursing students visit their dentists twice a year. It has been widely accepted that regular dental check-ups are necessary every 6 months, therefore this reported behavior obviously fails to follow these recommendations.

Considering the observed study programs, there are significant differences regarding dietary habits. The data show that-surprisingly-nursing students have poorer dietary habits. Beside playing an important role in maintaining the general health, healthy and balanced diet may have an important effect on one's intellectual achievements, emphasizing the importance of the right choice of nutrients in everyday life. ${ }^{27}$ It also important that all future health professionals have a healthy diet and promote healthy lifestyles. Smoking poses a risk factor for development of numerous oral diseases. According to the available data, the percentage of students who smoke varies significantly from 2.4 to $37 \%{ }^{28}$ Pacauskiene et $\mathrm{al}^{26}$ found that $26.7 \%$ of technical students smoke, compared with $9 \%$ of biomedical sophomores and $12 \%$ of final year students in biomedical programs. Our results showed no differences between students. Another problem among students is alcohol consumption. Changes in life circumstances, lack of parental surveillance, and increased stress lead to an increased intake of alcoholic beverages, leading to many undesired consequences. This investigation found significant differences regarding the observed study groups. Regarding the number of drinks per day, $12.5 \%$ of technical students say less than one per day versus $38.6 \%$ of nursing ones. This may at least partially be explained by the fact that nursing study programs are more frequently attended by female students. ${ }^{29}$

\section{Conclusion}

Results obtained and presented in this paper show better knowledge and more favorable habits and behaviors among the students from nursing study program compared with the technical ones. One of the possible reasons in the fact that nursing study program offer more educational subjects focusing on health and disease prevention, including oral health. Students are therefore educated on the right approach to health and disease, and analyze public health issues.

Oral health is an integral part of the overall health maintenance. Tooth decay is one of the most common oral problems and is considered as a huge public health problem in the whole world. Taking into account a high occurrence of tooth decay in the population, a more intensive general education should be deemed necessary. Students are particularly vulnerable groups, and they should be further educated through workshops. Furthermore, public actions should be taken more frequently, being provided with a greater media access, particularly for the oral health experts. Mandatory routine check-ups must be introduced for the most vulnerable groups, and dental examination should become an integral part of the standard medical examination.

\section{Funding \\ None.}

\section{Conflict of Interest}

None declared.

\section{References}

1 Petersen PE. The World Oral Health Report 2003: continuous improvement of oral health in the 21st century-the approach of the WHO Global Oral Health Programme. Community Dent Oral Epidemiol 2003;31(1, Suppl 1):3-23

2 Sabbah W, Folayan MO, El Tantawi M. The link between oral and general health. Int J Dent 2019:7862923

3 Saadeh R, Bober-Moken I, Challa S. Relationship between general health behaviors and oral health behaviors in 2015-2016 NHANES adult population. Eur J Dent 2019;13(3):405-412

4 Zheng S, Zhao L, Ju N, Hua T, Zhang S, Liao S. Relationship between oral health-related knowledge, attitudes, practice, self-rated oral health and oral health-related quality of life among Chinese college students: a structural equation modeling approach. BMC Oral Health 2021;21(1):99

5 Richards D. Oral diseases affect some 3.9 billion people. Evid Based Dent 2013;14(2):35

6 AlJehani YA. Risk factors of periodontal disease: review of the literature. Int J Dent 2014;2014:182513

7 Kumar M, Nanavati R, Modi TG, Dobariya C. Oral cancer: etiology and risk factors: a review. J Cancer Res Ther 2016;12(2):458-463 
8 Shah AF, Batra M, Sudeep CB, Gupta M, Kumar R. Oral habits and their implications. Ann Med 2014;1(4):179-186

9 Al-Wesabi AA, Abdelgawad F, Sasahara H, El Motayam K. Oral health knowledge, attitude and behaviour of dental students in a private university. BDJ Open 2019;5:16

10 Petersen PE. Sociobehavioural risk factors in dental caries - international perspectives. Community Dent Oral Epidemiol 2005;33(4):274-279

11 Petersen PE, Inequalities in oral health - the social context for oral health. In: Harris R, Pine C, eds. Community Oral Health. London: Quintessence; 2005

12 Al-Hussaini R, Al-Kandari M, Hamadi T, Al-Mutawa A, Honkala S, Memon A. Dental health knowledge, attitudes and behaviour among students at the Kuwait University Health Sciences Centre. Med Princ Pract 2003;12(4):260-265

13 Goldstein BY, Chang SC, Hashibe M. La Vecchia C, Zhang ZF. Alcohol consumption and cancers of the oral cavity and pharynx from 1988 to 2009: an update. Eur J Cancer Prev 2010;19(6):431-465

14 Gray JL, Maghlouth AA, Hussain HA, Sheef MA. Impact of oral and oropharyngeal cancer diagnosis on smoking cessation patients and cohabiting smokers. Tob Induc Dis 2019;17:75

15 Ashraf Nazir M, Almas K. Awareness about the effects of tobacco consumption on oral health and the possibility of smoking behavior among male Saudi schoolchildren. Eur J Dent 2017;11(1):29-35

16 Blaggana A, Grover V, Anjali, et al. Oral health knowledge, attitudes and practice behaviour among secondary school children in Chandigarh. J Clin Diagn Res 2016;10(10):ZC01-ZC06

17 Tanny L, Komabayashi T, Long DL, Yahata Y, Moffat SM, Tãne H. The effect of education on oral health students' attitudes in Australia and New Zealand. Eur J Dent 2016;10(4):491-495

18 World Health Organization: Oral health surveys. Basic Methods; 2013

19 Zhu L, Petersen PE, Wang HY, Bian JY, Zhang BX. Oral health knowledge, attitudes and behaviour of adults in China. Int Dent J 2005;55(4):231-241

20 Bandyopadhyay A, Bhuyan L, Panda A, Dash KC, Raghuvanshi M, Behura SS. Assessment of oral hygiene knowledge, practices, and concepts of tobacco usage among engineering students in Bhubaneswar, Odisha, India. J Contemp Dent Pract 2017;18(6):423-428

21 Birant S, Koruyucu M, Ozcan H, et al. Investigating the level of knowledge of the community about oral and dental health. Eur J Dent 2021;15(1):145-151

22 Buccheri G, Abt Gürber N, Brühwiler C. The impact of gender on interest in science topics and the choice of scientific and technical vocations. Int J Sci Educ 2011;33(1):159-178

23 Gopikrishna V, Bhaskar NN, Kulkarni SB. Knowledge, attitude, and practices of oral hygiene among college students in Bengaluru city. J Indian Assoc Publ Health Dent 2016;14(1):75-79

24 Jaramillo JA, Jaramillo F, Kador I, et al. A comparative study of oral health attitudes and behavior using the Hiroshima University-Dental Behavioral Inventory (HU-DBI) between dental and civil engineering students in Colombia. J Oral Sci 2013;55(1):23-28

25 Kaira LS, Srivastava V, Giri P, Chopra D. Oral health-related knowledge, attitude and practice among nursing students of Rohilkhand Medical college and hospital: a questionnaire study. J Orofac Res 2012;2(1):20-23

26 Pacauskiene IM, Smailiene D, Siudikienė J, Savanevskyte J, Nedzelskiene I. Self-reported oral health behavior and attitudes of dental and technology students in Lithuania. Stomatologija 2014;16(2):65-71

27 Reuter PR, Forster BL, Brister SR. The influence of eating habits on the academic performance of university students. J Am Coll Health 2020;6:1-7

28 Shah AH, ElHaddad SA. Oral hygiene behavior, smoking, and perceived oral health problems among university students. J Int Soc Prev Community Dent 2015;5(4):327-333

29 Davoren MP, Cronin M, Perry IJ, O’Connor K. Alcohol consumption among university students: a typology of consumption to aid the tailoring of effective public health policy. BMJ Open 2016;6(11):e011815 